\title{
Fenomenología
}

\section{Pietá: a representação imagética do cuidado ${ }^{1}$}

\section{Pietá: la representación de la imagen del cuidado \\ Pieta: the image representation of care}

Fernando Porto ${ }^{1}$; Mercedes Neto ${ }^{2}$ e Sandra Goulart Magalhães ${ }^{2}$.

${ }^{1}$ Doutor em Enfermagem com pós-doutoramento pela Escola de Enfermagem da Universidade de São Paulo. Professor Adjunto da Escola de Enfermagem Alfredo Pinto, da Universidade Federal do Estado do Rio de Janeiro.

${ }^{2}$ Doutorandas do Programa de Pós-Graduação em Enfermagem e Biociências da Universidade Federal do Estado do Rio de Janeiro do grupo de pesquisa LACENF.

Cómo citar este artículo en edición digital: Porto, F; Neto, M; Goulart Magalhães, S. (2013) Pietá: a representação imagética do cuidado. Cultura de los Cuidados.17, 37. Disponible en: <http://dx.doi.org/10.7184/cuid.2013.37.02>

Correspondencia: Fernando Porto. Escola de Enfermagem Alfredo Pinto - Universidade Federal do Estado do Rio de Janeiro. Av. Pasteur, 296 - Urca - Cep 22290-240.

Correo electrónico: Fernando Porto ramosporto@openlink.com.br Correo electrónico: marmagri@gmail.com. Teléfono: 5511989248960 - 551146202842

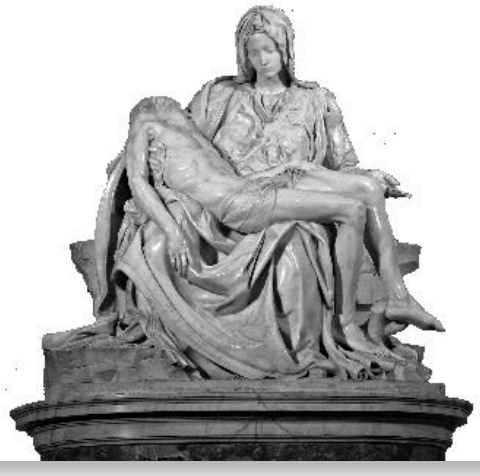

\section{ABSTRACT}

Reflection on the experience of care over time by the notions of care and time of the philosopher Paul Ricoeur. To this end, we used the image representation of Michelangelo's Pietá (1498), which resulted as a sign of respect Nursing decoded esteem, care, recognition of human value in themselves and in others, to overcome hatred, conflict, ignorance, by saying of love and justice, as conditions of realiza- tion of humanity as a contribution to building the image of the nurse.

Key words: Nursing, Nursing History and Image.

\section{RESUMEN}

La reflexión sobre la experiencia de los cuidados a través del tiempo por las nociones de la atención y el tiempo del filósofo Paul Ricoeur. Con este fin, se utilizó la representación de la imagen de la Pietá de Michelangelo (1498), que se tradujo como una señal de estima respecto de Enfermería decodificado, la atención, el reconocimiento del valor humano en sí mismos y en otros, a superar el odio, el conflicto, la ignorancia, al decir de amor y justicia, ya que las condiciones de realización de la humanidad como una contribución a la construcción de la imagen de la enfermera.

Palabras clave: Enfermería, Historia de la Enfermería y la imagen.

\footnotetext{
${ }^{1}$ Trabalho apresentado no III Simpósio Ibero-Americano de História da Enfermagem na mesa redonda intitulada "Historia y Fenomenología: la vivencia de los cuidados a través del tiempo". Alicante, 24 de novembro de 2011.
} 


\section{RESUMO}

Reflexão sobre a vivência do cuidado através do tempo pelas noções de cuidado e tempo do filósofo Paul Ricoeur. Para tanto, se utilizou a representação imagética de Pietá de Michelangelo (1498), que resultou como um signo da Enfermagem decodificado no respeito estima, solicitude, reconhecimento do valor humano em si e no outro, para superar o ódio, o conflito, o desconhecimento, pela afirmação do amor e da justiça, como condições de realização da humanidade, como contribuição para a construção da imagem da Enfermeira.

Palavras-chave: Enfermagem, História da Enfermagem e Imagem.

\section{CONSIDERAÇÕES INICIAIS}

Nos últimos tempos, do ano 2000, a análise da vivência do cuidado tem despertado nos pesquisadores de Enfermagem um sentido do bem estar, otimismo, esperança, entre outros fatores, seja de forma individual ou em grupo. Isto tem conduzido atitudes capazes de fazer alterações para o estímulo da criatividade e conhecimento, objetivando a participação dos envolvidos no cuidado para o alcance de mudança positiva, considerada como uma das tendências atuais (Borges e Silva, 2010).

Para tanto, a vivência do cuidado na formação do Enfermeiro torna-se relevante como estratégia pedagógica da ação no campo do Ensino Clínico ou Ensino Prático, no Brasil. Neste sentido, a vivência clínica na formação do enfermeiro foi objeto de análise, por meio da produção intelectual, no período de 2001 a 2006, na investigação intitulada "A vivência clinica na formação do enfermeiro". Esta identificou, no Catálogo de Dissertações e Teses do Centro de Estudos e Pesquisas da Associação Brasileira de Enfermagem - Nacional, o total de 132 estudos re- ferentes à vivência do cuidado (Landim, Silva e Batista, 2011).

O total da produção intelectual sobre a vivência clínica na formação do enfermeiro se encontra distribuída pelos estados brasileiros, a saber: São Paulo, Rio de Janeiro, Minas Gerais, Goiás, Paraná, Rio Grande do Sul, Santa Catarina, Bahia, Rio Grande do Norte, Ceará e Pernambuco, tendo em sua maioria a abordagem qualitativa. Ao final, dentre os resultados, os autores destacaram que, a vivência clínica é essencial para a formação do enfermeiro, possibilitando a competência clínica mediante articulação da eficiência e humanização (Landim, Silva, Batista, 2011).

Em outro estudo intitulado "Posicionamiento de linea de investigacion histórica: Magíster en Enfermería, Universidad de la Frontera Temuco Chile" a vivência do cuidado emergiu como categoria de análise, na perspectiva fenomenológica, por meio de análise de 18 pesquisas (2008-2011), ao desvelar a construção investigativa histórica dos mestrandos do Programa de Mestrado em Enfermagem, Gestão do Cuidado, que se inclui na linha de pesquisa histórica na área da saúde, relacionada à produção investigativa e sua difusão (Riveros e Riveros, 2011).

Cabe destacar que, vivência em alemão é "erlebins", que ao ser traduzido para a língua portuguesa, significa experiência vivida e experiência viva. A expressão designa toda atitude ou expressão da consciência, muito utilizada nas obras do alemão Dithhey como noção de instrumento fundamental da compreensão histórica e, em geral, da compreensão inter-humana, como unidade de atitude e conteúdo. Do mesmo modo, Husserl considerou como um fato da consciência entendido, como consciência em toda a sua plenitude concreta (Abbagnano, 2007). 
Maria Cecilia de Souza Minayo discutiu os fundamentos da pesquisa qualitativa no estudo intitulado "Los conceptos estructurantes de la investigación cualitativa", ao refletir sobre as suas bases estruturantes, fazendo o contraponto com as ciências compreensivas ao revisitar alguns filósofos e sociólogos no sentido de compreender de forma crítica a realidade no campo da linguagem (Minayo, 2011).

Destaca-se para o presente estudo a concepção de vivência. A pesquisadora ao discutir esta concepção se apoiou nos autores Dilthey, Gadamer, Heidegger e Schütz. Em síntese, a vivência é a experiência vivida e humana contida na formação da atuação de sua totalidade pela força psíquica, considerando que vivência e experiência se distinguem. A experiência se constitui de critério individual responsável pela caracterização do real articulada às condições históricas, que faz da vivência uma experiência individual carregada de sentido coletivo (Minayo, 2010; Siles \& Solano 2011).

Dito também como, o aprendido vivido pelo indivíduo e pelo grupo, expressado como sentido comum, instrumento primordial da narrativa das experiências e das vivências. Nesta perspectiva, o sentido comum representa o padrão cultural de grupo, que o indivíduo está vinculado e as suas tipificações, modos de viver, embasado na experiência e vivência (Minayo, 2011).

Ressalta-se que a palavra representação é um termo ambíguo. Por um lado, faz da realidade representada à evocação da ausência; por outro, torna visível a realidade representada, ao sugerir sua presença. Mas a contraposição pode ser também invertida, ou seja, a representação como presente, ainda, que sucedânea, e à realidade ausente que se pretende representar (Ginzburg, 2001).
No entendimento que a vivência é a experiência vivida e humana, característica do real e articulada às condições históricas, que faz dela uma experiência carregada de sentido coletivo, como instrumento da narrativa de experiências e de vivências, como sentido comum das tipificações dos modos de viver.

Para tanto, acredita-se que as narrativas, quando apresentadas pela linguagem imagética, podem possibilitar representações da vivência do cuidado através do tempo. Neste sentido, nas linhas que se seguem, o objetivo foi discorrer sobre a vivência do cuidado, por meio da representação imagética, através do tempo.

A justificativa para a realização deste deve-se a proposta no avanço do conhecimento da história e do cuidado, como uma das formas de contribuir na construção da História do Cuidado. Ademais, ele possibilita uma interface com outras áreas do conhecimento, o que pode contribuir na cultura dos cuidados.

\section{PAUL RICOEUR}

Para discorrer sobre a vivência do cuidado, por meio da representação imagética, através do tempo, adotou-se a noção de cuidado e tempo de Paul Ricoeur (1913-2005). Fenomenólogo de formação, que traduziu para o francês as ideias diretrizes para uma fenomenologia de Husserl, preocupado em atingir e formular uma teoria da interpretação do ser, ou seja, o da extração e da interpretação do sentido (Japiassú, 1996).

Convencido de que o pensamento moderno tornou-se interpretação, revisou a problemática da hermenêutica, passando a entendê-la como a teoria das operações de compreensão em sua relação com a interpretação dos textos. Ricoeur entendia o símbolo como expressão de nossa experiência funda- 
mental e situação no ser. Ademais, reintroduziu o estado nascente da linguagem, elaborando a filosofia da linguagem capaz de elucidar as múltiplas funções do significado humano (Japiassú, 1996).

Isto se deve, porque o símbolo conduz a pensar. Este pensamento consiste em decifrar o sentido oculto no sentido aparente pela visão antropológica, que contribuiu de forma corrosiva na psicanálise freudiana. Sua proposta de filosofia conduziu a atividade. Como tal, considerou-a como tarefa que e ao mesmo tempo concreta, temporal e pessoal com pretensões à universalidade (Japiassú, 1996).

\section{NOÇÃO DE CUIDADO E TEMPO DE PAUL RICOEUR}

Ricoeur adotava a noção de cuidado pelo respeito, estima, solicitude, reconhecimento do valor humano em si e no outro, para superar o ódio, o conflito, o desconhecimento, pela afirmação do amor e da justiça, como condições de realização da humanidade.

Nesta perspectiva, Ricoeur defendia que se fazia necessário um movimento duplo, que parte da ética do respeito que segue a fenomenologia da simpatia, retornando à ética, coordenando as duas, para alcançar o outro, podendo ser estranho a quem se cuida, por outro lado, trata-se de um nosso semelhante (Cesar, 2011).

O cuidado com o outro é o respeito a ele, pela sua natureza como fim em si, no entendimento que não se trata da realização de desejo de quem cuida, mas sim de quem é cuidado. Desta forma, ao se recuperar a simpatia, com cuidado e afeto, no âmbito do respeito ao outro, se articula o respeito imbricado à simpatia e reconhecimento do valor humano em si e no outro, como uma das formas de se superar o ódio e o desconhecimento, enquanto superação do conflito (Cesar, 2011).

Ricoeur cita que, na composição da noção do cuidado, a estima é o reconhecimento e atenção ao outro. Trata-se do fundamento do bem-viver, da amizade, da reciprocidade, da superação a violência. Dito em outras palavras, é o caráter insubstituível do outro enquanto pessoa (Cesar, 2011).

A solicitude é outro elemento que compõe a noção de cuidado. Esta se encontra no plano das relações inter-pessoais expressada na vida social, como: a igualdade e equidade, pois a justiça se sobrepõe. Neste sentido, a solicitude e respeito se destacam por meio da ética (Cesar, 2011).

Em suma, a noção de cuidado, para Paul Ricoeur se desdobra no tempo das relações do respeito, estima, solicitude, reconhecimento que estabelece o denominador comum em si própria, que ocorre e se aprofunda na recorrência dos temas multifacetados (Cesar, 2011).

Ricoeur entende o tempo, por meio da sua arquitetura, não como a fenomenologia do tempo vivido, nem com pelos exercícios de narratividade popular ou erudita, mas sim na ordem do pensável que ignora o sentido dos limites. Isto não quer significar que, a história pode se isolar na idéia de um espaço de extensão sem horizonte de expectativa, pois é por meio dos tempos que a história acumula os resultados e ao somar formam uma combinação favorável (Ricoeur, 2007).

\section{PIETÁ: REPRESENTAÇÃO IMAGÉTICA}

Para representar a imagética da vivência do cuidado, optou-se pela imagem da Pietá, de autoria de Michelangelo. Trata-se de uma escultura, nascida de um bloco de pedra Carrara, em 1498 de $1.74 m$ encomendada pelo 
cardeal francês San Diogini, representa a figura isolada de Maria, que tem nos braços o corpo de Cristo, logo após a retirada da cruz (Porto e Oguisso, 2011).

Nesta perspectiva, a imagem artística da escultura de Pietá (figura n. 1 ), por ser verossímil, remonta a passagem bíblica de mãe com seu filho nos braços. Esta escultura apresenta fisionomia de Maria extremamente jovem e calma, representando, possivelmente, a humanidade. A mão direita da madona sustenta com força o corpo inerte de seu filho, evidenciado pelos dedos abertos, dando relevo às costelas do Cristo. A fisionomia dele é de um homem abandonado, mas sereno (Barreto e Oliveira, 2004).

A opção na escolha se deve ao motivo por acreditar que, essa imagem possa representar um dos símbolos da vivência do cuidado através do tempo, que também por verossimilhança inspirou outras obras de arte, em especial, pela postura corporal adotada Maria com Cristo nos braços.

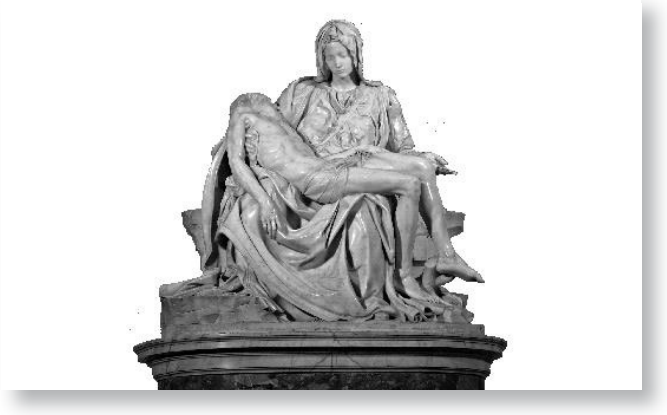

Figura 1 - Pietá de Michelangelo (1498)

A escultura é de estrutura triangular, bem como apresenta tamanho distinto da figura masculina, acomodada nos braços da mulher, que em relação à imagem feminina, transmite a mensagem de caridade e bondade, como o sentimento de piedade ao próximo e salvadora do mundo (Barreto e Oliveira, 2004; Porto e Santos, 2008).
Destarte, acredita-se que nada mais emblemático, que a imagem de Maria com Cristo em seus braços, como aliviadora do sofrimento da humanidade. Uma imagem que ignora o sentido dos limites na ordem do pensável, ao ponto de ser musa inspiradora para outras obras de arte por ser verossímil pela postura corporal.

No período da I Guerra Mundial (19141918) a Cruz Vermelha criou uma representação plástica de uma mulher denominada "Mãe do Mundo" (figura n. 2) veiculada na imprensa ilustrada brasileira acompanhada do texto, como o excerto, a saber: "mãe que embala nos braços e aconchega ao coração um soldado ferido, deitado na maca... nunca a arte encontrara uma tão comovedora interpretação plástica da humanista associação [Cruz Vermelha]" (Revista da Semana, 1918, 6).

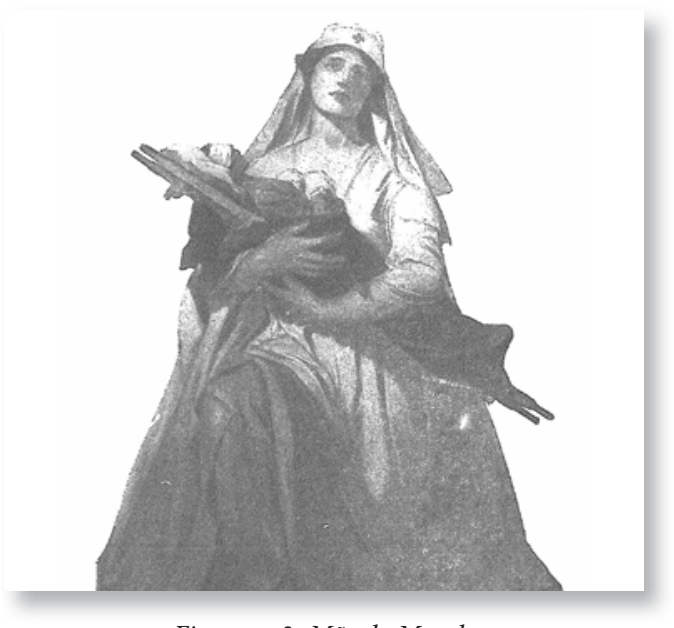

Figura n. 2- Mãe do Mundo

Em 1935, durante a realização da III Conferência Pan-Americana da Cruz Vermelha, no Rio de Janeiro, a Empresa de Correio e Telégrafo Brasileiro emitiu um selo comemorativo (Figura n. 3) no formato retangular de 0,40 $\mathrm{x} 0,22 \mathrm{~cm}$, tendo ao centro a figura de uma mulher, ostentando elementos simbólicos semelhante aos trajes da Enfermeira da Cruz 
Vermelha Brasileira, principalmente, no que se refere o véu e o símbolo institucional, com a inscrição em latim In Pace et in bello caritasNa paz e na guerra (Várzea, 1995).

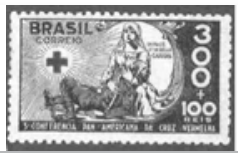

Figura n. 3- Selo da série III Conferência Pan-americana da Cruz Vermelha no Rio de Janeiro.

O selo tem a imagem de uma mulher em trajes que se remete à enfermeira da instituição com um ferido nos braços. A postura corporal dos personagens na composição da imagem é a mesma encontrada no alto da torre do Palácio da Cruz Vermelha Brasileira, no Órgão Central, localizado no Rio de Janeiro, que se aproxima da arte plástica veiculada na imprensa ilustrada denominada Mãe do Mundo (Figura n. 4) (Porto, 2009).

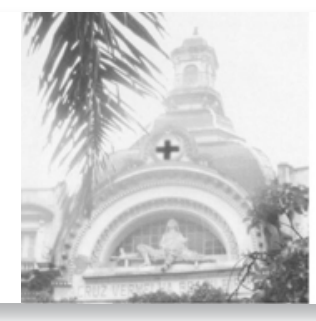

Figura n. 4 - Torre do Palácio da Cruz Vermelha Brasileira - Órgão Central - Rio de Janeiro (BR).

Em Madri, na Espanha, foi erguido o monumento em homenagem à Enfermeira Duquesa Vitória, oriunda do corpo de Enfermeiras da Cruz Vermelha Espanhola. A iniciativa para se erguer o monumento foi em 1925 de autoria dos escultores natural de Oviedo, em Astúrias, Julio Gonzalez e Garcia Póla. O monumento está localizado à frente da fachada entre os dois arcos que formam o portão principal do antigo Hospital Central da Cruz Vermelha ${ }^{2}$, atual Hospital de San José e Santa Adela, na Avenida de la Reina Victoria, em Madrid (Figura n. 5).

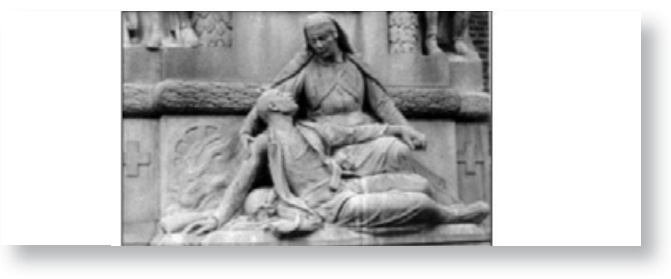

Figura n 5: (esquerdo) imagem da fachada do antigo Hospital Central da Cruz Vermelha, atual Hospital de San José e Santa Adela com o monumento a Enfermeira Duquesa Vitória (direito) imagem da estátua da enfermeira com um ferido de guerra em seus braços (Miralles-Sangro e Scribano, 2005)

O monumento é composto de quatro personagens em escultura que exige uma distância não muito longa para a sua contemplação. O primeiro patamar é apoiado no chão, o qual sustenta o monumento em uma pedra retangular de cerca de três metros de altura, contendo a inscrição onde se lê: "La Duquesa de la Victoria insigne bienhechora de los soldados heridos y enfermos por la campana de Marruecos la nación agradecida" (Miralles-Sangro e Scribano, 2005).

O corpo central do monumento é caracterizado por um forte sentido teatral. O grupo, de tamanho natural, expressa o valor de uma enfermeira que cuida de um soldado ferido

\footnotetext{
${ }^{2}$ O Hospital Central da Cruz Vermelha, chamado San José e Santa Adela, foi construído entre 1924 e 1928 pelo arquiteto Manuel Pastor Cardenas, em terrenos de propriedade da Companhia Urbanizadora Metropolitana, que foram doados à Cruz Vermelha. Stands em um piso em forma de "U" estruturado em torno de um jardim aberto à Avenida da Rainha Vitória a ser paga com fundos obtidos a partir de um saque especial da Loteria Nacional. A Direção-Geral da caridade deu a Suprema Assembléia da Cruz Vermelha, a Administração do Hospital, mais tarde conhecida como Hospital San Jose e San Adela.
} 
em batalha. A duquesa de Victoria é a enfermeira, trajando uma pelerine, embaixo dela o uniforme com um avental (fac-símile de número seis) (Miralles-Sangro e Scribano, 2005).

A postura corporal da enfermeira é de acolher em seus dois braços um homem ferido de guerra. O sentimento para quem o olha é de expressão de dor, mas sem prejuízo do conforto ao ferido. O soldado encontra-se caído em terra próximo a sua espingarda, apoiado em sua mochila, pedindo ajuda à enfermeira para salvar sua vida (Miralles-Sangro e Scribano, 2005).

No terceiro patamar do monumento, uma grande "front"eira de palma com folhas, símbolo do martírio, no qual sustenta uma grande cruz na cor vermelha sobreposta, onde se lê:

Este monumento fue inaugurado el 29 de junio de 1926 por S.M. la reina doña Victoria Eugenia bajo cuyo alto patrocinio alentados por su augusto ejemplo realizaron su piadosa y patriótica obra los hospitales de la cruz roja de toda Espana.

Destaca-se que, em 1920, por meio de um decreto real, o rei Alfonso XIII criou uma unidade militar com denominação “Tercio de Extranjeros”. Anos depois, em 1925, passou a ser chamada de "The Legion", quando se construiu o monumento, em 1937(Miralles-Sangro e Scribano, 2005).

\section{REPRESENTAÇÃO IMAGÉTICA DA VI- VÊNCIA DO CUIDADO ATRAVÉS DO TEMPO}

A imagem de Pietá quando encomendada pelo cardeal francês San Diogini, ele provavelmente transmitiu ao autor da obra da escultura, Michelangelo, detalhes de postura, vestes e outros que o artista, por meio de sua sensibilidade e também influencia de sua própria experiência, materializa a Pietá.
Esta escultura, como obra de arte, influenciou outras, como as expostas anteriormente pela verossimilhança da postura corporal em tempos diferentes, acredita-se pelo referencial de Ricoeur, transmitir o respeito, estima, solicitude, reconhecimento do valor humano no sentido de superar o ódio, o conflito, o desconhecimento, pelo amor e justiça como a vivência do cuidado, em que o tempo faz emergir a memória de quem a vê, a bondade e caridade, para com a humanidade.

Nesta compreensão, a bondade e a caridade podem ser entendidas também pelo perdão, mas antes de discorrer sobre este entendimento, se faz necessário certa digressão pela noção do trabalho de lembrança e trabalho de luto (Ricoeur, 2011).

O trabalho da lembrança é o uso critico da memória levado à linguagem - narrativa. Esta é a arte de narrar, contar história... Em contar a outrem histórias do passado, mas do ponto de vista do outro. O passado consistiu em contá-lo a outro e do ponto de vista do outro, assumindo a importância decisiva, quando se trata dos acontecimentos fundadores da História e da memória comuns. O trabalho de luto consiste em desligar-nos por graus do objeto de amor - o qual é também objeto de ódio -, até ao ponto em que poderá ser de novo interiorizado, num movimento de reconciliação semelhante ao que opera em nós o trabalho de lembrança. É na convergência das noções do trabalho da lembrança e de luto, que ocorre o perdão, além do domínio religioso, em virtude da sua generosidade.

Esta generosidade, que a narrativa da imagem da Pietá, transmite ao leitor pelas expressões faciais e postura corporal da imagem da escultura. Ricoeur relata que o trabalho interpretativo do leitor assume o caráter propriamente ético, na medida em que lhe permite 
averiguar o cumprimento ou não do pacto de leitura. Por isso, faz-se necessário estabelecer, teoricamente, o que implica interpretar um texto, em que consiste esta tarefa de leitura que a ele é solicitado (Ricoeur, 2007).

\section{CONSIDERAÇÕES FINAIS}

Nas reflexões teóricas feitas sobre a vivência do cuidado, por meio da representação imagética da escultura de Pietá de Michelangelo, através do tempo, optou-se pelas noções de cuidado e tempo de Paul Ricoeur, considerando as limitações sobre na abordagem fenomenológica, que se tratou ser um desafio e exercício intelectual por caminhos antes não trilhados.

A narrativa na linguagem imagética da escultura da imagem da Pietá é uma das possibilidades da representação da experiência vivida ou viva do cuidado, como uma das formas de expressão da consciência, que fundamentou a compreensão histórica de quem encomendou e a materializou a obra que ao longo do tempo vem representando, para a Enfermagem como um signo do cuidado.

Esta compreensão histórica representada na relação entre mãe e filho, que ao final da vida acalenta o corpo morto em seu colo. Postura corporal que no coletivo pode, em síntese, ser a representação narrativa simbólica sobre o cuidado, seja pelo olhar doméstico da mãe que cuida do seu filho, ou então, da Enfermagem que cuida do sujeito que é cuidado.

Esta narrativa imagética articulada à noção de cuidado de Ricoeur, por meio do respeito ao próximo, estima de reconhecimento ao outro, a solicitude representada na relação de mãe e filho, pela ética na vida social, foi a possibilidade de se fazer compreender a si mesmo pela generosidade do perdão e não pelo esquecimento.
$\mathrm{O}$ esquecimento que a memória reserva para se (re)construir a História do Cuidado, que também reserva significado em perceber e intuir, mesmo que em escala reduzida pela verossimilhança da realidade.

Esta verossimilhança, por meio dos rastros, às vezes, a mente humana pode não aceitar inteiramente como o real, pois cabe a ela conhecer o que é possível de se assimilar como fenômeno, em que a generosidade do perdão, possui significado muito além do domínio religioso através do tempo.

Neste sentido, o fenômeno do cuidado, ainda, tem muito a ser desvelado nas dobras do tempo e da filosofia, que a história, enquanto vivência é conhecimento. Aqui entendido como possibilidade de versões e interpretações para a trajetória do cuidado que é de interesse na área da saúde, mas, em especial, para a Enfermagem pelo que faz como ação ou intervenção, seja na promoção ou na reabilitação do sujeito que é cuidado.

Enfim, nesta perspectiva se tentou buscar outros significados para a vivência do cuidado, porém, em linguagem imagética como na representação da escultura de Pietá, podendo quiçá ser ela mais um dos signos do cuidado, que se vem tentando se desvelar, por meio do investimento imagético, o processo de construção da imagem da Enfermeira.

\section{REFERENCIAS}

- Abbagnano, N.(2007) Dicionário de Filosofia: São Paulo(Brasil): Martins Fontes.

- Barreto, G e Oliveira, MG. (2004) A arte secreta de Michelangelo: uma lição de anatomia na Capela Sistina. São Paulo(Brasil): Arx.

- Borges Z e Silva ME. (2010) Promover a esperança da família e resiliência. Práticas apreciativas. Investir Enferm Educ. 28 (2): 250-257

- Cesar, CM.(2008) A noção de cuidado em Paul Ricoeur. 
In: Caderno de resumo do V Encontro Lusobrasileiro de Bioética. UCP Porto (Portugal). Disponível:WWW. porto.ucp.pt/lusobrasileiro/actas/Constant\%C3A7a\%20 Marcondes.pdf. Capturado em 13 de novembro de 2011.

- Ginzburg, C. (2001) Representação - a palavra, a idéia, a coisa. In: Olhos de madeira - nove reflexões sobre a distância. São Paulo (Brasil). Companhia das letras: 85-103.

- Japiassú, H.(1996) Dicionário de Filosofia, Rio de Janeiro(Brasil). Zahar:236-237.

- Landim, SA, Silva, GTR e Batista, NA. (2011) A vivência clinica na formação do enfermeiro. In: Rev. Brasileira de Enfermagem. Brasília (Brasil). 64(3):558-62.

- Minayo, MC.(2010) Los conceptos estructurantes de la investigación cualitativa. In: Rev. Salud Colectiva. Buenos Aires (Argentina). 6(3): 251-261.

- Miralles-Sangro, MT e Escribano, MD. (2005) La enfermera em el monumento madrileno (1908-1936). Granada (Espanha): In Revista Index Enfermeira. 14(51). Disponível em http://scielo.isciii.es/scielo.php?script=sci_ar ttex\&pid=S1132-12962005000300014\&14\&1 ... Capturado em 10de junho de 2008.

- Porto, F e Oguisso, T. (2011) Os elementos simbólicos do monumento à Anna Nery no Rio de Janeiro (Brasil). In: Rev. Gaúcha de Enfermagem. Rio Grande do Sul (Brasil). (no prelo).

- Porto F, Santos TCF. (2008) A Enfermeira brasileira na mira do clik fotográfico (1919-1925). História da Enfer- magem - lutas, ritos e emblemas. Rio de Janeiro (Brasil). Águia Dourada: 25-188.

- Porto, F. (2009) Enfermagem: Cruz Vermelha e Anna Nery [relatório de pesquisa de pós-doutoramento]. São Paulo (Brasil). Universidade de São Paulo.

- Revista da Semana. (1918) O altruísmo da mulher brasileira. Rev Semana. Rio de Janeiro (Brasil). (19) 39: 06.

- Riveros, ER e Riveros, ER. (2011) Posicionamiento de linea de investigacion histórica: Magíster en Enfermería, Universidad de la Frontera Temuco Chile.In: Historia y desarrollo de la profesión y de enfermería científica. Disponivel: www.esenfc.pt/.../exportAbstractPDF.php?id... Capturado 2 de outubro de 2011.

- Ricoeur, P. (2007) A memória, a história, o esquecimento. Campinas (Brasil). Unicamp.

- Ricoeur, P. (2011) O perdão pode curar? Disponível:: www.lusosofia.net. Capturado em: 1 de novembro de 2011.

- Siles, J. e Solano, C. (2011) A história cultural e a estética dos cuidados de enfermagem. Rev Lat Am Enfermagem; 19(5): 1096-1105. Disponivel: http://www.scielo.br/ scielo.php?pid=S0104-11692011000500006\&script=sci_ arttext\&tlng=es

- Várzea MPN. (1995) As mulheres de bronze [dissertação]. Rio de Janeiro (Brasil). Departamento de História da Pontifica Universidade Católica do Rio de Janeiro/ PUC-RJ. 